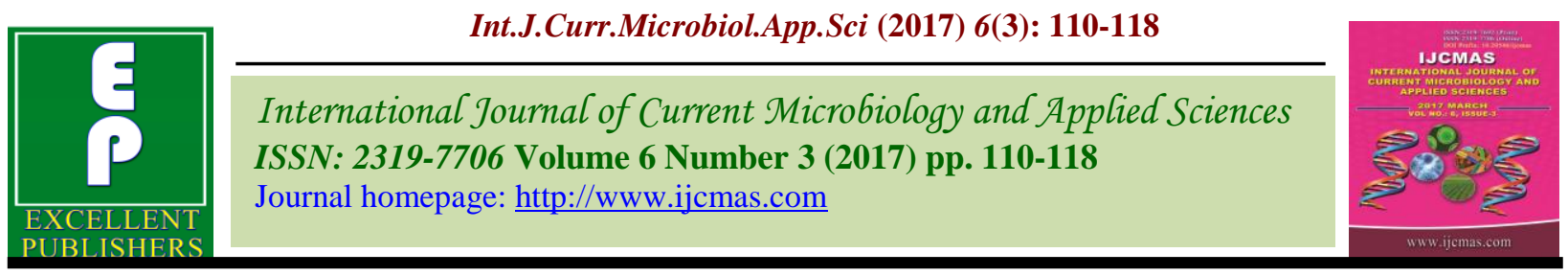

Original Research Article https://doi.org/10.20546/ijcmas.2017.603.012

\title{
Production of $\alpha$-L-Rhamnosidase from Aspergillus flavus: Optimization of Submerged Culture Conditions by Taguchi DOE Methodology
}

\author{
Poonam Yadav ${ }^{1}$, Anil Kumar Chauhan ${ }^{1}$, Mohammed A. Al-Sebaeai ${ }^{1}$ and Suman Yadav ${ }^{2}$ \\ ${ }^{1}$ Centre of Food Science and Technology, Banaras Hindu University, Varanasi-221005, India \\ ${ }^{2}$ Department of Microbiology, SGPGIMS, Lucknow-226014, India \\ *Corresponding author
}

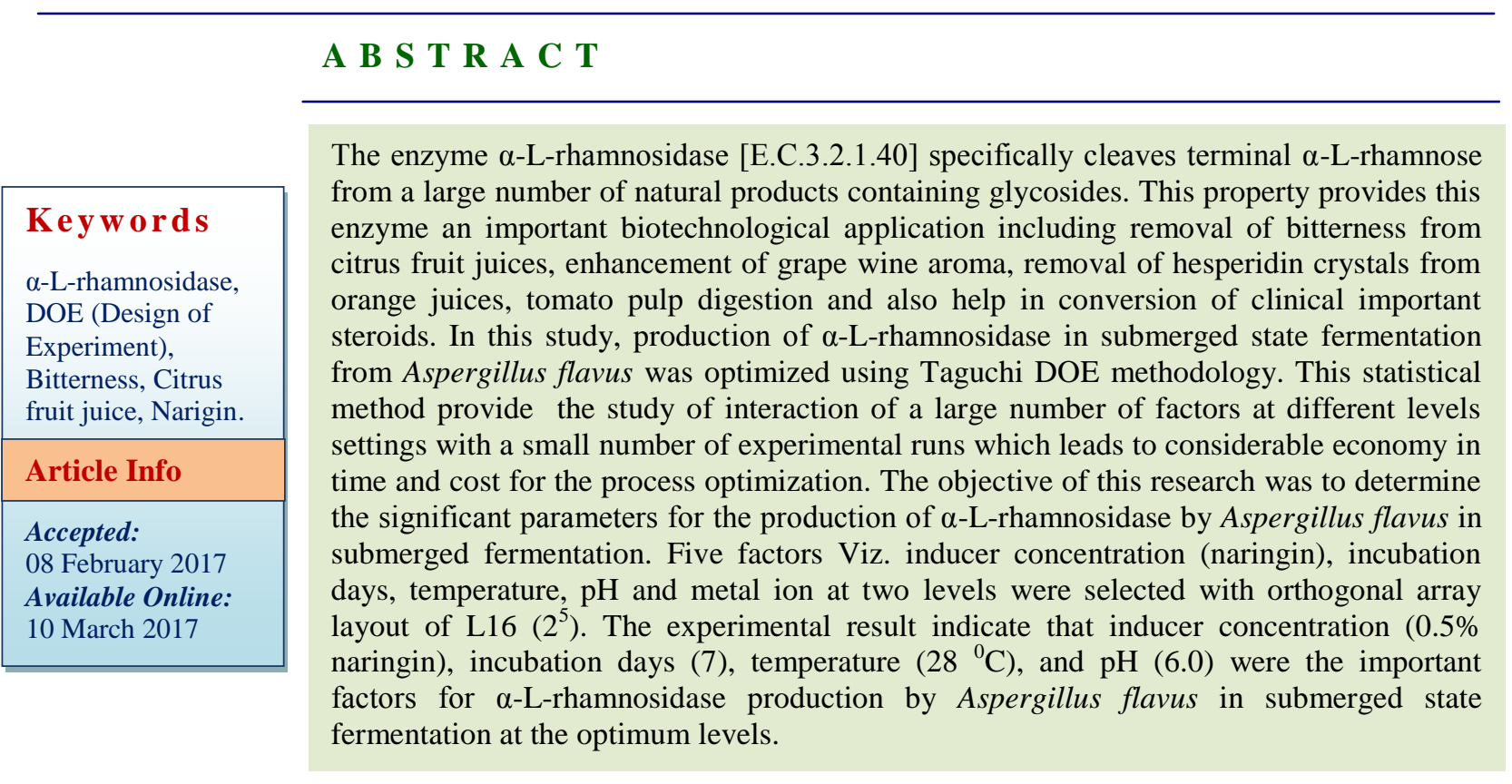

\section{Introduction}

The biotechnological potential of microbial enzymes has drawn a great deal of attention from various researchers worldwide, as they are likely to be biological catalysts in a variety of industrial processes, high production yields, easy genetic manipulation, provide regular production due to independent of geographical condition, fast growth of microorganism in inexpensive media, more convenient and safer protection methods. Among microbial enzymes, $\alpha$-Lrhamnosidase [E.C.3.2.1.40] which cleaves terminal $\alpha$-L-rhamnose from a large number of natural glycosides includes mainly naringin, rutin, hesperidin quercitrinand terpenyl glycosides (Yadav et al., 2010). This enzyme is a part of an enzyme complex called naringinase. Naringinase has two subunits: $\alpha-$ L-rhamnosidase which hydrolyzenaringin to rhamnose and prunin, which are further converted into glucose and naringenin by another subunit $\beta$-D-glucosidase [EC.3.2.1.21] (Puri et al., 2005). This enzyme has been reported in literature from various 
sources such as plants, animal tissue, yeast, fungi and bacteria.

$\alpha$-L-rhamnosidase has several applications in food industry mainly removal of bitter compound naringin from citrus fruit juice by converting to less bitter compound prunin (Puri et al., 2010) and elimination of hesperidin crystals from citrus juices (Miyake et al., 1999). In wine industry, $\alpha$-Lrhamnosidase play important role in aroma enhancement of grape fruit wine (Manzanares et al., 2000), in pharmaceuticals industry it's used for derhamnosylation of natural compound containing the L-rhamnose residues in the terminal and biotransformation of steroids and antibiotics (Thirkettle, 2000).

Among fungi, Aspergillus flavus is very prominent producer of $\alpha$-L-rhamnosidase. It is well known that $\alpha$-L-rhamnosidase is an extracellular enzyme which production in submerged fermentation is greatly affected by inducer concentration, incubation days, $\mathrm{pH}$, temperature and metal ions. Conventional optimization procedures involve changing of one factor at a time keeping all other parameters constant. These processes are very time consuming, complicated, and require more experimental data sets and also can't provide more information about interaction of the factors (Beg et al., 2003). However, for optimization of all factors and establishment the best possible conditions by considering all interaction of parameters, numerous experiments have to be carried out, which is not economical and practical.

Alternative to conventional optimization procedures, Taguchi Design of experiments (DOE) provide more information about the optimization process in a few trials (Krishna et al., 2005). Statistical experimental design methods provide an efficient and systematic plan for optimization of culture conditions by considering the interactive effects among the control factors. Several control factors can be simultaneously analysed and optimized by statistical experimental design tool in Taguchi DOE (Rao et al., 2004; Abdel et al., 2005).

In this study, Taguchi Design of Experiment (Minitab 17) was used to optimize the submerged culture conditions for the production of $\alpha$-L-rhamnosidase. The experiments were designed for five factors inducer concentration, incubation days, temperature, $\mathrm{pH}$ and metal ion at two levels with orthogonal array layout of L16.

\section{Materials and Methods}

\section{Chemicals}

Naringin and $\quad p$-nitrophenyl- $\quad \alpha$-Lrhamnopyranoside were obtained from Sigma, India. The other culture media (Potato dextrose Agar, Czapek Dox Broth) and different carbon and nitrogen sources were obtained from Hi-Media. All other reagents were used of analytical grade.

\section{Microorganism and culture media}

The fungal strain used in present study, Aspergillus flavus was screened and isolated from decaying lemon peel and culture was maintained at $4{ }^{0} \mathrm{C}$ in Potato Dextrose Agar slants (PDA) throughout the experiments and sub-cultured in every two weeks.

\section{Production of $\alpha$-L-rhamnosidase}

The production of $\alpha$-L-rhamnosidase enzyme was done in the submerged culture condition in which Czapek Dox Broth was used. $100 \mathrm{ml}$ of culture media in $250 \mathrm{ml}$ Erlenmeyer flask was inoculated with $5 \mathrm{~mm}$ bead size of 48 hours grown isolated fungal strain from PDA plate. Different concentrations of inducer (naringin) range between 0.3 and $0.5 \%$ were used for enzyme production. The flask was 
incubated in B.O.D incubator at $28^{\circ} \mathrm{C}$ in stationary conditions. The crude enzyme was obtained by centrifugation of the culture broth at $10000 \mathrm{rpm}$ for 10 minutes at $4^{0} \mathrm{C}$. The supernatant which contains the enzymes was assayed for $\alpha$-L-rhamnosidase activity.

\section{Enzyme assay}

The activity of $\alpha$-L-rhamnosidase was assayed by Davis method (1947) in which naringin was used as a substrate. The reaction solution constituted of $1.0 \mathrm{~mL}$ of $5 \%$ naringin dissolved in $0.1 \mathrm{M}$ sodium acetate buffer, $\mathrm{pH}$ 4.0, maintained at $50{ }^{\circ} \mathrm{C}$ for 1 hour. $0.2 \mathrm{~mL}$ of enzyme extract was added to the above solution. From the incubated mixture, $0.1 \mathrm{ml}$ was added to $5 \mathrm{ml}$ of $90 \%$ diethylene glycol containing $0.1 \mathrm{ml} 4 \mathrm{M} \mathrm{NaOH}$. After 10 minutes at room temperature, the residual naringin, the intensity of the resultant yellow colour, was measured at $420 \mathrm{~nm}$. One unit of $\alpha$-L-rhamnosidase activity (U) is defined as the amount of enzyme that could hydrolyze one micromole of naringin per minute at the assay conditions. Another method was also used to check the activity of $\alpha$-Lrhamnosidase enzyme by using synthetic substrate $\quad p$-nitrophenyl- $\alpha$-lrhamnopyranoside and monitored the liberation of $p$-nitrophenolate ion spectrophotometrically at $400 \mathrm{~nm}$, molar extinction coefficient value of $21.44 \mathrm{mM}^{-1}$ $\mathrm{cm}^{-1}$ (Romero et al., 1985).

\section{Optimization methodology}

Minitab 17 Taguchi software (e-academy) was used to optimize the $\alpha$-L-rhamnosidase production with the help of Taguchi Design of Experiment. In this experimental design a standard orthogonal array L16 $\left(2^{5}\right)$ with 15 degree of freedom was used to examine five factors at two levels. The $\mathrm{L}$ and the subscript (16) represent the Latin square and the number of experimental runs, respectively.
The levels of the factors studied and the layout of the L16 Taguchi's OA, orthogonal array are shown in tables 1 and 2.

The experimental results were analysed to find out the effects of main factors; the analysis of variance (ANOVA) was then applied to know which factors were statistically significant. The controlling factors were identified, and then optimized statistically significant variables. Also the optimum conditions were determined by combining the different levels of factors that showed the highest main effect value.

\section{Results and Discussion}

Taguchi experimental design is a good statistical tool for the optimization of biotechnological processes for production of microbial enzymes. It is the sequence of steps which initially identify the factors to be optimized and then test condition to ensure that the data obtained in this analysis will lead to valid statistical interpretation.

In this study, the influence of 5 factors on the $\alpha$-L-rhamnosidase production by Aspergillus flavus was tested in Taguchi experimental design in 16 runs by using Minitab 17 software (e-academy).

The results of Taguchi experimental design in 16 runs, for the five factors, inducer concentration (naringin), incubation days, temperature, $\mathrm{pH}$ and metal ion at two level selected for optimization of $\alpha$-L-rhamnosidase production by the fungal strain Aspergillus flavus (Table 2) show the efficiency of $\alpha$-Lrhamnosidase production ranging from 0.40 $-3.88 \mathrm{U} / \mathrm{mL}$ corresponding to the combined effect of the five factors in their specific ranges. The experimental results justified that these factors at optimized level support the production of $\alpha$-L-rhamnosidase. 
In run 2, inducer concentration (0.3\% naringin), incubation days (4), temperature $\left(25^{\circ} \mathrm{C}\right), \mathrm{pH}(6)$ and metal ion $(0.07 \%)$, showed lowest production $0.40 \mathrm{U} / \mathrm{ml}$ was observed. The production of $3.88 \mathrm{U} / \mathrm{ml}$ was observed in run 16 with a combination of inducer concentration $(0.5 \%$ naringin), incubation days (7), temperature $\left(28^{\circ} \mathrm{C}\right), \mathrm{pH}$ (6) and metal ion $(0.07 \%)$. Figure 1 represents the contribution of selected factors for the $\alpha$-Lrhamnosidase production in submerged state fermentation. It can be observed that inducer (naringin), incubation days, $\mathrm{pH}$ and temperature respectively contributing of 25.35 $\%, 21.11 \%, 18.56 \%$ and $18.32 \%$ have shown highest positive impact on the $\alpha$-Lrhamnosidase enzyme production. Metal ions showed least impact among the factors studied with the assigned variance of values. Therefore, the analysis of variance (ANOVA) for the responses of $\alpha$-L-rhamnosidase production was carried out according to the factors which contributed more than $10 \%$ as suggested by the Taguchi method.

In Taguchi Design of Experiments, ANOVA was used to analyze the results of the Orthogonal Array experiments and determine how much variation of each factor has contributed. By studying the main effects of each and every factors, the general trends of the influence of the factors towards the process can be categorized. The characteristics can be controlled such that a lower or a higher value in a particular influencing factor produces the significant result. Thus, the levels of factors to give the best results can be predicted (Krishna et al., 2005).

Analysis of the data for the determination of significant parameters on $\alpha$-L-rhamnosidase production and the results are shown in ANOVA table 3. From the calculated ratios $(F)$, it can be referred that the factors considered in the Taguchi experimental design are statistically significant at $95 \%$ confidence limit. The ANOVA of $\alpha$-Lrhamnosidase production has the model Fvalue of 137.94 that implies the model is significant. The model obtained from ANOVA indicated that the multiple correlation coefficient of $\mathrm{R}^{2}$ is 0.9857 i.e. the model can explain $98.57 \%$ variation in the response. Also, the model has an adequate precision value of 9.371 ; this suggests that the model can be used to navigate the design space. The adequate precision value is define as an index of the signal to noise ratio and the value of signal to noise ratio should be greater than 4 then the model is good fit. The model shows standard deviation, mean, coefficient of variance and predicted residual sum of square (PRESS) values of 6.20, 121.57, 4.47 and 324.79 respectively. Point prediction for achieving highest $\alpha$-L-rhamnosidase enzyme production in terms of levels of factors is shown in table 4. Under optimal conditions for $\alpha$-L-rhamnosidase, the expected activity was $3.88 \mathrm{U} / \mathrm{mL}$.

Figures 2 represent the main effect plots for the means which show how each factor affects the response characteristic. A main effect is present when different levels of a factor affect the characteristic differently. MINITAB 17 creates the main effects plot by plotting the characteristic average for each factor level. A line connects the points for each factor. When the line is parallel to the $\mathrm{x}$ axis, i.e. horizontal, it showed there is no main effect present.. When the line is not parallel to the $\mathrm{x}$-axis, it shows that there is a main effect present. Different levels of the factor affect the characteristic differently. The greater the difference in the vertical position of the plotted points i.e. to parallel $\mathrm{x}$ - axis, the greater is the magnitude of the main effect was shown in the figure 2 . 
Table.1 Factors and their levels employed in the Taguchi experimental design method for optimization of $\alpha$-L-rhamnosidase production from Aspergillus flavus in submerged state fermentation

\begin{tabular}{|l|c|c|}
\hline Factors & Level 1 & Level 2 \\
\hline Inducer (Naringin) & $0.3 \%$ & $0.5 \%$ \\
\hline Incubation Days & 4 & 7 \\
\hline Temperature $\left({ }^{0} \mathrm{C}\right)$ & 25 & 28 \\
\hline $\mathrm{pH}$ & 5 & 6 \\
\hline Metal Ion $(0.07 \%)$ & $\mathrm{Ca}^{++}$ & $\mathrm{Cu}^{++}$ \\
\hline
\end{tabular}

Table.2 L16 (25) orthogonal array of Taguchi design of experiments and corresponding $\alpha$-L-rhamnosidase production from Aspergillus flavus in submerged state fermentation

\begin{tabular}{|c|c|c|c|c|c|c|}
\hline Run & $\begin{array}{c}\text { Inducer } \\
(\% \text { of } \\
\text { Naringin) }\end{array}$ & $\begin{array}{c}\text { Incubation } \\
\text { Days }\end{array}$ & $\begin{array}{c}\text { Temperature } \\
\left({ }^{\mathbf{0}} \mathbf{C}\right)\end{array}$ & $\mathbf{p H}$ & $\begin{array}{c}\text { Metal } \\
\text { Ions } \\
\mathbf{( 0 . 0 7 \%})\end{array}$ & $\begin{array}{c}\text { Response } \\
\text { Enzyme } \\
\text { Activity } \\
(\mathbf{U} / \mathbf{m l})\end{array}$ \\
\hline 1. & 0.3 & 4 & 25 & 5 & $\mathrm{Ca}^{++}$ & 0.48 \\
\hline 2. & 0.3 & 4 & 25 & 6 & $\mathrm{Cu}^{++}$ & 0.40 \\
\hline 3. & 0.3 & 4 & 28 & 5 & $\mathrm{Cu}^{++}$ & 0.62 \\
\hline 4. & 0.3 & 4 & 28 & 6 & $\mathrm{Ca}^{++}$ & 0.68 \\
\hline 5. & 0.3 & 7 & 25 & 5 & $\mathrm{Cu}^{++}$ & 1.13 \\
\hline 6. & 0.3 & 7 & 25 & 6 & $\mathrm{Ca}++$ & 1.91 \\
\hline 7. & 0.3 & 7 & 28 & 5 & $\mathrm{Ca}++$ & 1.82 \\
\hline 8. & 0.3 & 7 & 28 & 6 & $\mathrm{Cu}++$ & 1.72 \\
\hline 9. & 0.5 & 4 & 25 & 5 & $\mathrm{Cu}++$ & 2.28 \\
\hline 10. & 0.5 & 4 & 25 & 6 & $\mathrm{Ca}++$ & 2.80 \\
\hline 11. & 0.5 & 4 & 28 & 5 & $\mathrm{Ca}++$ & 2.68 \\
\hline 12. & 0.5 & 4 & 28 & 6 & $\mathrm{Cu}++$ & 2.88 \\
\hline 13. & 0.5 & 7 & 25 & 5 & $\mathrm{Ca}++$ & 3.38 \\
\hline 14. & 0.5 & 7 & 25 & 6 & $\mathrm{Cu}++$ & 3.11 \\
\hline 15. & 0.5 & 7 & 28 & 5 & $\mathrm{Cu}++$ & 3.32 \\
\hline 16. & 0.5 & 7 & 28 & 6 & $\mathrm{Ca}++$ & 3.88 \\
\hline
\end{tabular}


Table.3 ANOVA for $\alpha$-L-rhamnosidase production by Aspergillus flavus

\begin{tabular}{|l|c|c|l|l|c|}
\hline \multicolumn{9}{|l|}{ Analysis of Variance (ANOVA) } \\
\hline Source & DF & $\begin{array}{l}\text { Sum of } \\
\text { Square }\end{array}$ & $\begin{array}{l}\text { Mean } \\
\text { Square }\end{array}$ & F-Value & P-Value \\
\hline Model & 10 & 19.1604 & 3.8321 & 137.94 & $0.002^{*}$ \\
\hline Inducer & 2 & 15.0156 & 15.0156 & 540.52 & $0.003^{*}$ \\
\hline Incubation Days & 2 & 3.4040 & 3.4040 & 122.54 & $0.001^{*}$ \\
\hline Temperature & 2 & 0.2601 & 0.2601 & 9.36 & $0.012^{*}$ \\
\hline $\mathrm{pH}$ & 2 & 0.3906 & 0.3906 & 14.06 & $0.004^{*}$ \\
\hline Metal Ion. & 2 & 0.0900 & 0.0900 & 3.24 & 0.102 \\
\hline Residual & 5 & 0.2778 & 0.0278 & & \\
\hline Total & 15 & 19.4382 & & & \\
\hline
\end{tabular}

Abbreviation: * Significant

Table.4 Point prediction for optimum conditions of $\alpha$-L-rhamnosidase production from Aspergillus flavus in submerged state fermentation

\begin{tabular}{|c|c|c|c|c|c|}
\hline & Prediction & SE Mean & $\begin{array}{l}95 \% \text { CI } \\
\text { Low }\end{array}$ & $\begin{array}{l}95 \% \text { CI } \\
\text { High }\end{array}$ & Optimum conditions \\
\hline $\begin{array}{l}\alpha-\mathrm{L}- \\
\text { rhamnosidase } \\
\text { activity } \\
(\mathrm{U} / \mathrm{ml})\end{array}$ & 2.99327 & 0.850891 & 109.785 & 188.965 & $\begin{array}{l}\text { Inducer (Naringin } 0.5 \%) \text {, } \\
\text { Incubation days }(7), \\
\text { Temperature }\left(28{ }^{0} \mathrm{C}\right), \mathrm{pH}(6), \\
\mathrm{Ca}^{++}(0.07 \%)\end{array}$ \\
\hline
\end{tabular}

Abbreviation: SE: Standard Error, CI: Confidence Interval

Figure.1 Contribution of five factors on $\alpha$-L-rhamnosidase production from Aspergillus flavus in a submerged culture using Taguchi experimental design

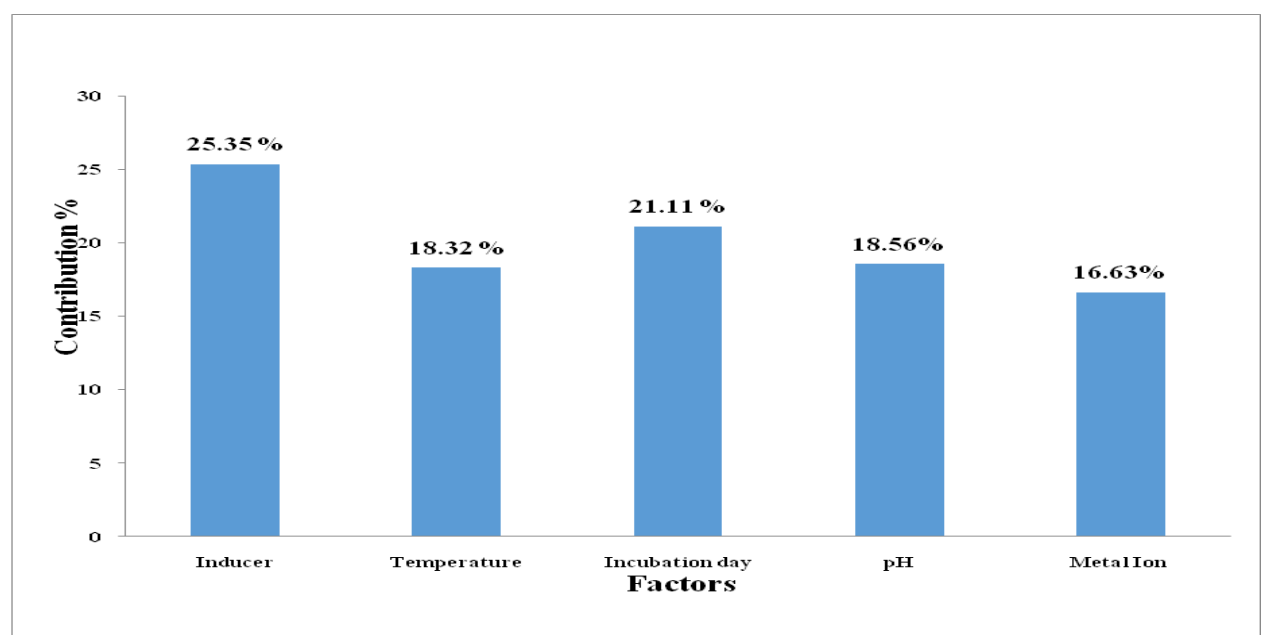


Figure.2 Graph showing the effect of each factor contribution in the $\alpha$-L-rhamnosidase enzyme production by Aspergillus flavus in submerged state fermentation

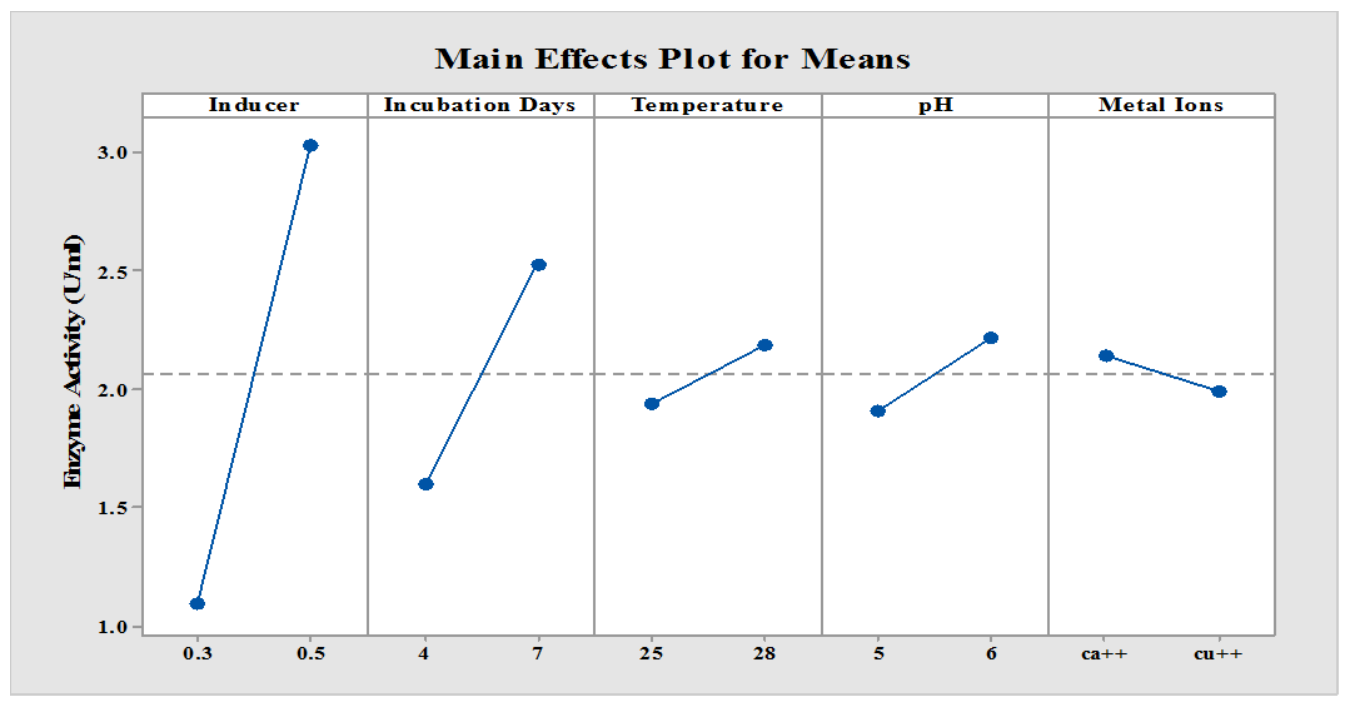

Each microorganism has its own special conditions for maximum enzyme production. The isolated fungus Aspergillus flavus from decaying citrus peel showed the highest enzyme activity when media composition is optimized. Although fungi of the genera Penicillium have been also reported as producers of this enzyme (Elinbaum et al., 2002). Aspergillus genus had been used preferentially for $\alpha$-L-rhamnosidase enzyme production for a number of years. This is because of its high level of extracellular enzyme production seen in this genus. In this study, Taguchi Design of Experiment for $\alpha$-Lrhamnosidase production by Aspergillus flavus and reported this experiment design provided basic information to improve the efficiency of $\alpha$-L-rhamnosidase production and also supported the analysis of the main factor of each constituent of the medium. Adriana et al., (2014) also successfully applied Taguchi experimental design for $\alpha$-Lrhamnosidase production by Aspergillus niger and observed enhanced production.

Among various statistical designs of experimental methods, Taguchi DOE is the most reliable statistical method and offers enhanced yields in just few experimental trials that provide the interactive effects among the various process factors and their levels. It's reduces both the time required for achieving optimum activity of enzyme and as well as cost of production. It is reported that statistical DOE have been employed for increasing production yields in different studies (Kunamneni et al., 2005). Any particular factor may interact with each other's and then provide the possibility of presence of interactions among them. This type of interaction is possible in Taguchi design of experiment. The estimated interaction severity index (SI) of the factors understudy helps to know about the influence of two individual factors at various levels of the interactions (Koo et al., 2006).

In this study, $\alpha$-L-rhamnosidase production by Aspergillus flavus in submerged state fermentation, inducer concentration $(0.5 \%$ naringin), incubation days (7), temperature $\left(28{ }^{\circ} \mathrm{C}\right), \mathrm{pH}(6)$ and metal ion $(0.07 \%)$ up to level 2, constituted the main factors of the medium. The contribution of five factors in $\alpha$ L-rhamnosidase production by Taguchi experimental design showed that inducer concentration (naringin) played a leading role than the other selected parameters (inducer 
(naringin) $25.35 \%$,incubation days $21.11 \%$, $\mathrm{pH} 18.56 \%$ and temperature $18.32 \%$ and metal ions $16.63 \%$ ). Point prediction of the design showed that maximum $\alpha$-Lrhamnosidase production of $2.99 \mathrm{U} / \mathrm{mL}$ was achieved under optimal experimental conditions. This result would further provide economic design of the large scale fermentation operation system for biotechnology processes.

In conclusion, Taguchi Design of Experiment (DOE) by using Minitab 17 was successfully applied in this study to test the relative importance of medium components and factors on $\alpha$-L-rhamnosidase production. The selected orthogonal array was L16 $\left(2^{5}\right)$ and optimum factors for $\alpha$-L-rhamnosidase production were found to be inducer (naringin), incubation days, temperature and $\mathrm{pH}$. The optimum medium condition derived was: inducer concentration $(0.5 \%$ naringin $)$, incubation days $(7)$, temperature $\left(28{ }^{\circ} \mathrm{C}\right)$, and $\mathrm{pH}$ (6). At this optimum condition, the yield of $\alpha$-L-rhamnosidase production by Aspergillus flavus was found to be 3.88 $\mathrm{U} / \mathrm{mL}$.

\section{Acknowledgement}

One of the author, Poonam Yadav want to thanks the Department of Science and Technology (DST), Government of India, for awarding DST-INSPIRE fellowship for financial support to carry out this work at Centre of Food Science and Technology, Banaras Hindu University, Varanasi.

\section{References}

Abdel, F.Y.R., Saeed, H.M., Gohar, Y.M. and El-Baz M.A. 2005. Improved production of Pseudomonas aeruginosauri case by optimization of process parameters through statistical experimental designs. Process
Biochem., 40: 1707-1714.

Beg, K., Sahai, V., Gupta, R. 2003. Statistical media optimization and alkaline protease production from Bacillus mojaensisin a bioreactor. Proc. Biochem., 39: 203-209.

Davis, D.W. 1947. Determination of flavonones in citrus juice, Anal Chem., 19: 46-48.

Elinbaum, S., Ferreyra, H., Ellenrieder, G., and Cuevas, C. 2002. Production of Aspergillusterreusa-L-rhamnosidase by solid state fermentation. Lett. Appl. Microbiol., 34(1): 67-71.

Koo, T.Y., Lin, I.P., Liu, H.R. and Chou, C.Y. 2006. Determination of nattokinase production condition using taguchi parameter design. Food Sci. Technol. Int., 12(3): 215-220.

Krishna, P.K., Venkata, M.S., Sreenivas, R.R., Ranjan, P.B. and Sarma, P.N. 2005. Laccase production by Pleurotusostreatus 1804: Optimization of submerged culture conditions by Taguchi DOE methodology. Biochem. Eng. J., 24: 17-26.

Kunamneni, A., Kumar, K.S., and Singh, S. 2005. Response surface methodological approach to optimize the nutritional parameters for enhanced production of $\alpha$-amylase. African J. Biotechnol., 4(7): 708 -716.

Manzanares, P., Orejas, M., Ibanez, E., Vallés, S., Ramón, D. 2000. Purification and Characterization of an $\alpha-\mathrm{L}-$ Rhamnosidase from Aspergillus nidulans. Lett. Appl. Microbiol., 31: 198-202.

Miyake, T., Yumoto, T. 1999. Enzyme treated hesperidin, process for producing the same and method for using enzyme. US Patent, 885-969.

Petri, A.C., Buzato, J.B., Celligoi, M.A.P.C. and Borsato, D. 2014. Optimization of the Production of $\alpha$-L-Rhamnosidase by Aspergillus niger in Solid State 
Fermentation Using Agro-Industrial Residues. British Microbiol. Res. J., 4(11): 1198-1210.

Puri, M., Banerjee, A., Banerjee, U.C. 2005. Optimization of Process Parameters for the Production of Naringinase by Aspergillus niger MTCC 1344. Process Biochem., 40: 195-201.

Puri, M., Kaur, A., Singh, R.S., Nahar, A 2010. Response surface optimization for the production of naringinase from Staphlococcus xylosus MAK2. Appl. Biochem. Biotechnol., 162: 181-191.

Rao, R.S., Prakasham, R.S., Prasad, K.K., Rajesham, S., Sarma, P.N. and Rao, L.V. 2004. Xylitol production by Candida sp.: parameter optimization using Taguchi approach. Process Biochem., 39: 951-956.

Romero, C., Manjon, A., Bastida, J., Iborra, J.L.1985. A method for assaying rhamnosidase activity of naringinase. Anal. Biochem., 149: 566-571.

Thirkettle, J. 2000. SB-253514 and analogues novel inhibitors of lipoprotein associated phospholipase A2 produced by Pseudomonas fluorescens M11579. III. Biotransformation using naringinase. J. Antibiot., 53: 733-735.

Yadav, V., Yadav, P.K., Yadav, S., Yadav, K.D.S. 2010. $\alpha$-LRhamnosidase: A review. Process Biochem., 45: 12261235.

\section{How to cite this article:}

Poonam Yadav, Anil Kumar Chauhan, Mohammed A. Al-Sebaeai and Suman Yadav. 2017. Production of $\alpha$-L-Rhamnosidase from Aspergillus flavus: Optimization of Submerged Culture Conditions by Taguchi DOE Methodology. Int.J.Curr.Microbiol.App.Sci. 6(3): 110-118. doi: https://doi.org/10.20546/ijcmas.2017.603.012 